
DENPASAR TIMUR

\author{
Ni Putu Emy Darma Yanti ${ }^{1}$, Ida Ayu Laksmi Mahardika ${ }^{2}$, Ni Ketut Guru Prapti ${ }^{3}$ \\ ${ }^{1,2,3}$ Program Studi IImu Keperawatan Fakultas Kedokteran Universitas Udayana
}

\begin{abstract}
ABSTRAK
Hipertensi menjadi salah satu penyakit tidak menular yang menjadi perhatian utama karena angka kejadian yang tinggi di dunia. Salah satu terapi non farmakologis hipertensi yang dapat dilakukan adalah slow deep breathing yang merupakan metode relaksasi yang dapat mempengaruhi barorefleks tubuh dan menurunkan tekanan darah. Tujuan penelitian ini adalah untuk mengetahui pengaruh pemberian slow deep brething terhadap tekanan darah pada penderita hipertensi di wilayah kerja Puskesmas I Denpasar Timur. Penelitian ini merupakan penelitian kuantitatif dengan jenis penelitian pre-eksperimental. Desain yang digunakan adalah one group pre test post test design dengan intervensi berupa latihan slow deep breathing selama 21 hari 2 kali dalam sehari. Jumlah sampel dalam penelitian ini adalah 28 orang berusia 35-80 tahun yang dipilih dengan teknik sampling probability sampling jenis simple random sampling. Waktu penelitian berlangsung 28 hari dari tanggal 28 Maret sampai 25 April 2016. Teknik analisis data yang digunakan dalam penelitian ini adalah analisis univariat untuk karakteristik responden dan analisa bivariate untuk pengaruh slow deep breathing terhadap tekanan darah. Uji bivariate menggunakan Wilcoxon karena data tidak terdistribusi normal, dengan hasil nilai signifikan $(p)=0,000$ yang berarti $p<0,05$ dengan tingkat kesalahan $5 \%$ maka $\mathrm{H}_{0}$ (nol) ditolak. $\mathrm{H}_{0}$ (nol) ditolak artinya slow deep breathing memberi pengaruh terhadap tekanan darah pada penderita hipertensi. Kesimpulannya adalah ada pengaruh pemberian slow deep breathing terhadap tekanan darah pada penderita hipertensi. Berdasarkan hasil penelitian dapat disarankan penggunaan slow deep breathing sebagai terapi non farmakologis untuk hipertensi.
\end{abstract}

Kata Kunci: Hipertensi, tekanan darah, slow deep breathing.

\title{
THE INFLUENCE OF SLOW DEEP BREATHING ON BLOOD PRESSURE OF HYPERTENSION PATIENT
}

\begin{abstract}
Hypertension is one of non-communicable diseases, which is become major interest because mortality and morbidity of hypertension is the highest in the world. Slow deep breathing is non pharmacology therapy that can influence baroreflex and decrease the blood pressure. This research aimed to know the influence of slow deep breathing on blood pressure of hypertension patient in Puskesmas I Denpasar Timur. This research was pre experimental quantitative study. Design of this study was using one group pre test post test design with the intervention was slow deep breathing during 21 days, twice a day. The amount of sample in this study was 28 patients, in 35-80 years old which is chosen by simple random sampling technique. This research was conducted from March $28^{\text {th }}$ until April $25^{\text {th }} 2016$. Univariate test was used to analyze respondent's characteristics and bivariate test was used to analyze the difference of systolic and diastolic blood pressure to pre test and post test. The Bivariate test was using Wilcoxon because the data wasn't normal distributed. The result of bivariate test was significant ( $p$-value $=0,000$ ), with level of confidence $5 \%$ so $\mathrm{H}_{0}$ was rejected. The conclusion of this study: there was influence of slow deep breathing in decrease the blood pressure of hypertension patients in Puskesmas I Denpasar Timur. Based on the result of this study, It is suggested to use slow deep breathing as non pharmacology therapy for hypertension.
\end{abstract}

Key Word: Blood Pressure, Hypertension, Slow Deep Breathing

Corresponding Author :

Ni Putu Emy Darma Yanti ${ }^{1}$, Program Studi Ilmu Keperawatan Fakultas Kedokteran Universitas Udayana; e-mail emydarmayanti@gmail.com 


\section{PENDAHULUAN}

Hipertensi menjadi salah satu penyakit tidak menular yang menjadi perhatian utama karena angka kejadian yang tinggi di dunia. World Health Organisation (WHO) tahun 2012 menyatakan bahwa angka kejadian hipertensi mencapai 50\% dari total penduduk dunia. Prevalensi kejadian hipertensi di Indonesia meningkat setiap tahunnya. Kementerian Kesehatan RI (2013) menyatakan bahwa terjadi peningkatan prevalensi hipertensi dari 7,6\% tahun 2007 menjadi 9,5\% pada tahun 2013.

Dinas Kesehatan Provinsi Bali (Dinkes Bali) mencatat kejadian hipertensi di seluruh Provinsi Bali pada tahun 2014 berjumlah 114.421. Data yang diperoleh melalui Dinas Kesehatan Kota Denpasar (Dinkes Denpasar) sepanjang tahun 2014 tercatat sebanyak 4.048 kasus hipertensi primer pada laki-laki dan 4.685 kasus hipertensi primer pada perempuan (Dinkes Denpasar, 2015).

Hasil studi pendahuluan yang telah dilakukan peneliti pada bulan Agustus 2015 di Puskesmas I Denpasar Timur didapatkan data kasus hipertensi pada tahun 2013 berjumlah 1.531 kasus dan meningkat pada tahun 2014 menjadi 4.144 kasus. Penderita hipertensi pada bulan Juli tahun 2015 berjumlah 142 orang.

Hipertensi dapat menjadi ancaman serius bila tidak ditangani. Tekanan darah tidak terkontrol akan mengakibatkan stroke, infark miokard, gagal ginjal, ensefalopati, dan kejang (Tambayong, 2010). Penyempitan pembuluh darah akibat hipertensi dapat menyebabkan berkurangnya suplai darah dan oksigen ke jaringan yang akan mengakibatkan mikroinfark pada jaringan (Price \& Wilson, 2006). Komplikasi berat hipertensi adalah kematian karena obstruksi dan rupturnya pembuluh darah otak (Price \& Wilson, 2006).

Pengobatan hipertensi secara farmakologis standar yang dianjurkan oleh Komite Dokter Ahli hipertensi yaitu obat diuretik, penyekat beta, antagonis kalsium, dan penghambat ACE (Angiotensin Converting Enzyme) (Gunawan, 2007). Terapi nonfarmakologis yang wajib dilakukan oleh penderita hipertensi yakni mengontrol asupan makanan dan natrium, menurunkan berat badan, pembatasan konsumsi alkohol dan tembakau, serta melakukan latihan dan relaksasi (Smeltzer \& Bare, 2011). Salah satu terapi nonfarmakologis yang dapat dilakukan pada penderita hipertensi primer yaitu latihan slow deep breathing karena termasuk ke dalam latihan dan relaksasi (Joseph, et al., 2006; Kaushik, Kaushik, Mahajan, \& Rajesh, 2006; Sepdianto, Nurachmah, \& Gayatri, 2010).

Slow deep breathing adalah relaksasi yang disadari untuk mengatur pernapasan secara dalam dan lambat (Martini, 2006). Slow deep breathing yang dilakukan sebanyak enam kali permenit selama 15 menit memberi pengaruh terhadap tekanan darah melalui peningkatkan sensitivitas baroreseptor dan menurunkan aktivitas sistem saraf simpatis serta meningkatkan aktivitas sistem saraf 
parasimpatis pada penderita hipertensi primer (Joseph et al., 2006; Sepdianto, Nurachmah, \& Gayatri, 2010).

Khausik et al (2006) melakukan penelitian dengan memberikan latihan slow deep breathing dan mental relaksation pada penderita hipertensi primer selama 10 menit memberi dampak terhadap tekanan darah sistolik dan diastolik, suhu tubuh, denyut nadi, serta pernafasan. Oleh karena itu, peneliti tertarik melakukan penelitian mengenai Pengaruh Pemberian Slow Deep Breathing Terhadap Tekanan Darah pada Penderita Hipertensi Primer di Wilayah Kerja Puskesmas I Denpasar Timur khususnya pada wilayah kelurahan Sumerta. Tujuan penelitian ini adalah untuk mengetahui pengaruh pemberian slow deep brething terhadap tekanan darah pada penderita hipertensi di wilayah kerja Puskesmas I Denpasar Timur.

\section{METODE}

Penelitian ini merupakan penelitian pre-eksperimental dengan desain one group pre test post test design. Penelitian ini dilakukan untuk mengukur tekanan darah pada penderita hipertensi sebelum diberikan latihan slow deep breathing dan membandingkannya dengan tekanan darah penderita hipertensi sesudah latihan slow deep breathing selama 21 hari.

Populasi penelitian ini adalah penderita hipertensi primer di wilayah kerja Puskesmas I Denpasar Timur yang bertempat tinggal di kelurahan Sumerta. Populasi target dalam penelitian ini berjumlah 40 orang. Teknik pengambilan sampel dalam penelitian ini adalah probability sampling jenis simple random sampling. Besar sampel dalam penelitian ini menggunakan rumus uji hipotesis beda rata-rata berpasangan, yaitu berjumlah 28 orang.

Penelitian ini dilaksanakan di kelurahan Sumerta wilayah kerja Puskesmas I Denpasar Timur. Penelitian ini dilakukan selama 28 hari yaitu pada tanggal 28 Maret sampai 25 April 2016.

Variabel yang diteliti dalam penelitian ini yaitu tekanan darah sebagai variabel dependen dan slow deep breathing sebagai variabel independen. Instrumen yang digunakan dalam penelitian ini adalah tensi meter air raksa sebagai alat untuk mengukur tekanan darah dan lembar observasi untuk mengumpulkan data karakteristik beserta hasil pengukuran tekanan darah responden.

Peneliti mengurus ijin penelitian dan penyamaan persepsi dengan enumerator, kemudian menyeleksi sampel, dan memberikan inform consent. Setelah mendapat persetujuan, responden diukur tekanan darahnya dalam posisi duduk kemudian diberi latihan slow deep breathing selama 15 menit. Latihan slow deep breathing dilakukan dua kali dalam sehari selama 21 hari. Hari terakhir latihan slow deep breathing dilakukan pengukuran tekanan darah untuk menilai tekanan darah setelah latihan slow deep breathing pada sore hari. Setelah data terkumpul, peneliti memasukan data ke dalam master tabel kemudian menguji normalitas data. 
Peneliti melakukan entry data, coding, editing dan cleaning terhadap data yang telah dikumpulkan kemudian melakukan analisis data. Teknik analisis data yang digunakan dalam penelitian ini adalah teknik analisis univariat dan bivariat, dengan melakukan uji normalitas terlebih dahulu.

Uji normalitas data dilakukan terhadap data tekanan darah sebelum dan sesudah diberikan latihan slow deep breathing dengan menggunakan uji Shapiro Wilk karena jumlah sampel kurang dari 50 orang. Hasil analisis distribusi data menunjukkan data tidak berdistribusi normal ( $p$ value $<0,05$ ) sehingga dilakukan uji non parametrik dengan uji Wilcoxon.

\section{HASIL}

\section{Hasil Pengamatan terhadap Karakteristik Responden}

Karakteristik responden berdasarkan usia, jenis kelamin, dan pola hidup yang telah diteliti didistribusikan sebagai berikut:

a. Karakteristik responden berdasarkan usia

Tabel 1 Distribusi Frekuensi Responden Berdasarkan Usia

\begin{tabular}{cccc}
\hline No. & Rentang Usia (th) & Frekuensi (n) & $\begin{array}{c}\text { Presentase } \\
\text { (\%) }\end{array}$ \\
\hline 1 & $26-35$ & 2 & 7,1 \\
2 & $46-55$ & 9 & 32,1 \\
3 & $56-64$ & 8 & 28,6 \\
4 & $65-90$ & 9 & 32,1 \\
\hline \multicolumn{5}{r}{ Total } & $\mathbf{2 8}$ & $\mathbf{1 0 0 , 0}$ \\
\hline
\end{tabular}

Tabel 1 menunjukkan karakteristik responden berdasarkan usia. Rentang usia terbanyak adalah 4655 tahun dan 65-90 tahun dengan presentase $32,1 \%$.

b. Karakteristik responden berdasarkan jenis kelamin

Tabel 2 Distribusi Frekuensi Responden Berdasarkan Jenis Kelamin

\begin{tabular}{cccc}
\hline No. & Jenis Kelamin & Frekuensi $(\mathbf{n})$ & $\begin{array}{c}\text { Persentase } \\
\text { (\%) }\end{array}$ \\
\hline 1. & Laki-laki & 12 & 42,9 \\
2. & Perempuan & 16 & 57,1 \\
\hline & Total & $\mathbf{2 8}$ & $\mathbf{1 0 0}$ \\
\hline
\end{tabular}

Table 2 menunjukkan jumlah responden dalam penelitian ini sebagian besar berjenis kelamin perempuan yaitu 16 orang atau $57,1 \%$ dari total responden. 
c. Karakteristik responden berdasarkan pola hidup

Tabel 3 Distribusi Frekuensi Responden Berdasarkan Pola Hidup

\begin{tabular}{cccc} 
No. & Pola Hidup & Frekuensi (n) & $\begin{array}{c}\text { Persentase } \\
\text { (\%) }\end{array}$ \\
\hline 1. & Minum Kopi & 14 & 50,0 \\
2. & Merokok & 1 & 3,6 \\
3. & Alkohol & 0 & 0 \\
4. & Tidak ada & 13 & 46,4 \\
\hline & Total & $\mathbf{2 8}$ & $\mathbf{1 0 0 \%}$ \\
\hline
\end{tabular}

Table 3 menunjukkan pola hidup yang paling banyak dilakukan oleh responden adalah kebiasaan minum kopi yaitu sebanyak 14 orang atau $50 \%$ dari total responden. Tidak ada responden yang memiliki kebiasaan minum alkohol.

\section{Hasil Pengamatan terhadap Tekanan Darah Sebelum Pemberian Latihan Slow Deep Breathing}

Tabel 4 Tekanan Darah Pre Test pada Pasien Hipertensi di Wilayah Kerja Puskesmas I Denpasar Timur

\begin{tabular}{|c|c|c|c|c|}
\hline Variabel & $\mathbf{N}$ & Mean & Min & Max \\
\hline Tekanan Darah sistolik & 28 & 150,71 & 140 & 170 \\
\hline Tekanan Darah diastolik & 28 & 94.64 & 90 & 100 \\
\hline
\end{tabular}

Table 4 menunjukkan rata-rata tekanan darah sistolik pre test pada responden yaitu $150,71 \mathrm{mmHg}$, sedangkan rata-rata tekanan darah diastolik pre test adalah $94,6 \mathrm{mmHg}$.

Hasil Pengamatan terhadap Tekanan Darah Setelah Pemberian Latihan Slow Deep Breathing

Tabel 5 Tekanan Darah Post Test pada Pasien Hipertensi di di Wilayah Kerja Puskesmas I Denpasar Timur

\begin{tabular}{ccccc}
\hline Variabel & N & Mean & Min & Maks \\
\hline Tekanan Darah Sistolik & 28 & 132,68 & 120 & 150 \\
\hline Tekanan Darah Diastolik & 28 & 83,04 & 80 & 95 \\
\hline
\end{tabular}

Table 5 menunjukkan Tekanan darah sistolik post test terendah adalah $120 \mathrm{mmHg}$ dan tertinggi sebesar $150 \mathrm{mmHg}$. Tekanan darah diastolik post test terendah sebesar $80 \mathrm{mmHg}$ dan tertinggi $95 \mathrm{mmHg}$. 


\section{Hasil Analisis Data Responden Berdasarkan Perbedaan Tekanan Darah Pre test dan Post test}

Tabel 6 Hasil Analisis Uji Wilcoxon dan Selisih Tekanan Darah Pre test dan Post test pada Pasien Hipertensi di Wilayah Kerja Puskesmas I Denpasar Timur.

\begin{tabular}{ccccccc}
\hline Indikator & N & Mean & Min & Max & Z & $\boldsymbol{p}$ \\
\hline SelisihTD sistolik & 28 & 18,04 & 10 & 30 & $-4,713$ & .000 \\
\hline Selisih TD diastolik & 28 & 11,61 & 5 & 20 & $-4,917$ & .000 \\
\hline
\end{tabular}

Table 6 menunjukkan hasil analisis nilai tekanan darah sistolik dan diastolik sebelum dan sesudah diberikan latihan slow deep breathing. Hasil analisis data yang dilakukan dengan menggunakan uji Wilcoxon test dengan $\alpha=0,05$ mendapatkan nilai z sebesar $-4,731$ untuk tekanan sistolik dan nilai z sebesar -4,917 untuk tekanan darah diastolik. Nilai z bernilai negative (-) menunjukkan penurunan tekanan darah setelah diberikan latihan slow deep breathing.

Uji statistik terhadap nilai tekanan darah sistolik dan diastolik sebelum serta sesudah latiahan slow deep breathing mendapatkan hasil yaitu nilai signifikan $(p)=0,000$ yang berarti terdapat perbedaan tekanan darah sistolik dan diastolik yang bermakna antara sebelum serta setelah intervensi

\section{PEMBAHASAN}

\section{Karakteristik Responden Berdasarkan Usia, Jenis Kelamin, dan Pola Hidup}

Usia responden dalam penelitian ini berada dalam rentang 35-80 tahun. Rentang usia terbanyak adalah usia 46-55 tahun dan 65-90 tahun. Hal ini sesuai dengan teori yang menyatakan kejadian hipertensi semakin meningkat seiring dengan meningkatnya usia (Tambayong, 2010).

Faktor jenis kelamin juga mempengaruhi kejadian hipertensi. Pria lebih banyak mengalami hipertensi ketika usia pertengahan, sedangkan wanita lebih banyak mengalami hipertensi ketika memasuki usia lanjut (diatas 65 tahun) (Tambayong, 2010). Teori tersebut sejalan dengan hasil penelitian ini yaitu sebagian besar responden berjenis kelamin perempuan sebanyak 16 orang.

Smeltzer dan Bare (2011) menyebutkan beberapa faktor yang berperan dalam terjadinya hipertensi adalah gangguan emosi, obesitas, konsumsi alkohol yang berlebihan, rangsangan kopi yang berlebihan, tembakau dan obat-obatan. Teori ini mendukung hasil penelitian yaitu 
14 orang responden dalam penelitian ini memiliki kebiasaan minum kopi, merokok satu orang dan 13 orang responden tidak memiliki kebiasaan merokok dan minum kopi.

\section{Tekanan Darah Pre Test}

Rata-rata tekanan darah sistolik responden sebelum perlakuan adalah $150,71 \mathrm{mmHg}$ dan rata-rata tekanan darah diastolik sebelum perlakuan adalah 94,64mmHg. Didapatkannya perbedaan tekanan darah dari setiap responden karena ada beberapa faktor yang mempengaruhi besarnya tekanan darah setiap orang. Hal ini sesuai dengan teori yang menyatakan bahwa terdapat faktor-faktor yang mempengaruhi besarnya tekanan darah setiap orang yaitu faktor usia, jenis kelamin, dan medikasi (Potter \& Perry, 2006). Pola hidup dan ras juga menjadi faktor risiko terjadinya hipertensi (Smeltzer \& Bare, 2011).

\section{Tekanan Darah Post test}

Rata-rata tekanan darah sistolik post test pada responden yaitu $132,68 \mathrm{mmHg}$ dan rata-rata tekanan darah diastolik post test $83,04 \mathrm{mmHg}$. Hasil pengukuran tekanan darah post test pada penelitian ini sejalan dengan hasil penelitian yang dilakukan oleh Anderson et al. (2010) tentang pengaruh latihan rutin slow deep breathing terhadap tekanan darah dengan rata-rata tekanan darah sistolik post test adalah $153 \mathrm{mmHg}$ dan tekanan darah diastolik post test $96 \mathrm{mmHg}$.

\section{Pengaruh Latihan Slow Deep Breathing Terhadap Penurunan Tekanan Darah pada Penderita Hipertensi di Wilayah Kerja Puskesmas I Denpasar Timur}

Uji statistik terhadap nilai tekanan darah sistolik dan diastolik sebelum serta sesudah latiahan slow deep breathing mendapatkan perbedaan nilai signifikan antara tekanan darah pre test dan post test yang artinya ada pengaruh latihan slow deep breathing terhadap penurunan tekanan darah pada pasien hipertensi.

Slow deep breathing termasuk ke dalam salah satu metode relaksasi. Pada saat relaksasi terjadi perpanjangan serabut otot, menurunnya pengiriman implus saraf ke otak, menurunnya aktivitas otak, dan fungsi tubuh yang lain, krakteristik dari respon relaksasi ditandai oleh menurunnya denyut nadi, jumlah pernafasan dan penurunan tekanan darah (Potter \& Perry, 2006). Penelitian mengenai slow deep breathing yang dilakukan oleh Critchley, et all tahun 2015 mendapatkan hasil slow deep breathing dapat memengaruhi cortex cerebri dan bagian 
medulla yang positif berhubungan dengan relaksasi sistem saraf yang mampu memengaruhi mekanisme penurunan tekanan darah.

Latihan nafas (breathing exercise) yang dijadikan kebiasaan bernafas dapat meningkatkan kesehatan baik fisik maupun mental (Potter \& Perry, 2006). Slow deep breathing berpengaruh terhadap modulasi sistem kardiovaskular yang akan meningkatkan fluktuasi dari interval frekuensi pernafasan dan berdampak pada peningkatan efektifitas barorefleks serta dapat berkontribusi terhadap penurunan tekanan darah (Sepdianto, Nurachmah, \& Gayatri, 2010). Mason et al tahun 2013 dalam artikel penelitian mengenai yoga dan slow deep breathing menyatakan slow deep breathing memberi pengaruh terhadap peningkatan respon sensitivitas baroreflex, penurunan tekanan darah, mengurangi ansietas, dan meningkatkan saturasi oksigen. Penelitian ini juga menunjukkan bahwa penurunan tekanan darah lebih signifikan saat jumlah inspirasi dan ekspirasi sama atau seimbang.

Pengaruh slow deep breathing terhadap sensitivitas barorefleks terbukti secara signifikan berpengaruh. Respon sensitivitas barorefleks meningkatkan pengaruh slow deep breathing terhadap penurunan tekanan darah dalam 24 jam pengukuran. Barorefleks akan mengaktifkan sistem parasimpatis yang mengakibatkan vasodilatasi pembuluh darah, penurunan output jantung dan akan mengakibatkan tekanan darah menurun (Fatimah \& Setiawan, 2009). Pernafasan yang dalam dan lambat akan meningkatkan kadar oksigen dalam tubuh dan merangsang kemoreseptor tubuh. Rasangan pada kemoreseptor tubuh akan mengakibatkan respon vasodilatasi pembuluh darah dan menurunan tekanan vaskular sehingga tekanan darah turun (Fatimah \& Setiawan, 2009).

Slow deep breathing memberikan efek kepada sistem saraf dan mempengaruhi pengaturan tekanan darah. Slow deep breathing menurunkan aktivitas saraf simpatis melalui peningkatan central inhibitory rythms yang akan berdampak pada penurunan output simpatis (Fatimah \& Setiawan, 2009; Joseph et al., 2006). Penurunan output simpatis akan menyebabkan penurunan pelepasan epinefrin yang ditangkap oleh reseptor alfa sehingga mempengaruhi otot polos pembuluh darah (Fatimah \& Setiawan, 2009; Joseph, et al., 2005). Otot polos vaskular mengalami vasodilatasi yang akan menurunkan tahanan perifer dan menyebabkan penurunan tekanan darah (Fatimah \& Setiawan, 2009; Joseph et al., 2006). Oleh karena itu latihan slow deep breathing dapat digunakan sebagai terapi nonfarmakolgis pada penderita hipertensi baik yang mengkonsumsi obat ataupun tidak mengkonsumsi obat. 


\section{SIMPULAN DAN IMPLIKASI PENELITIAN}

Pemberian slow deep breathing selama 21 hari sebanyak dua kali dalam sehari memberi pengaruh terhadap tekanan darah responden. Rata-rata perbedaan tekanan darah sistolik sebelum dan sesudah perlakuan adalah $18,04 \mathrm{mmHg}$. Rata-rata perbedaan tekanan darah diastolik sesudah perlakuan adalah $11,61 \mathrm{mmHg}$. Hasil uji statistik yaitu nilai signifikan $(p)=0,000$ yang berarti $p<0,05$ dengan tingkat kesalahan $5 \%$ maka $\mathrm{H}_{0}$ (nol) ditolak. $\mathrm{H}_{0}(\mathrm{nol})$ ditolak artinya slow deep breathing memberi pengaruh terhadap tekanan darah pada penderita hipertensi. Kesimpulannya adalah ada pengaruh pemberian slow deep breathing terhadap tekanan darah pada penderita hipertensi.

Penelitian ini memiliki beberapa keterbatasan oleh karena itu perlu disempurnakan sehingga bagi peneliti selanjutnya agar lebih mengembangkan karakteristik dan kehomogenan responden serta mengontrol jenis pola hidup lain seperti nutrisi, kurang aktivitas dan tidak berolahraga yang dapat menjadi faktor risiko penyebab dari hipertensi sehingga perlu dikontrol. Saran bagi peneliti selanjutnya agar mengatur diet makanan dan diet garam dari setiap responden.

\section{DAFTAR PUSTAKA}

Anderson, D.E., Mcneely, J.D., Windham, B.G.J., \& Hum, H. ( 2008). Regular slowbreathing exercise effects on blood pressure and breathing patterns at rest. Epub, 24(12) : 80-713.Doi:10.1038/jhh.http://www.ncbi.nlm.nih.gov/pubmed/20200548.

Critchley, H. D., Nicotra, A., Chiesa, P. A., Nagai, Y., Gray, M. A., Minati, L., \& Bernardi, L. (2015). Slow breathing and hypoxic challenge: Cardiorespiratory consequences and their central neural substrates. PLoS One, 10(5) doi:http://dx.doi.org/10.1371/journal.pone.0127082

Dinas Kesehatan Provinsi Bali. (2014). Profil Kesehatan Provinsi Bali 2013. Denpasar: Dinas Kesehatan Provinsi Bali.

Dinas Kesehatan Kota Denpasar. (2015). Profil Kesehatan Kota Denpasar 2014. Denpasar: Dinas Kesehatan Kota Denpasar.

Fatimah, S. \& Setiawan, R. (2009). Fisiologi kardiovaskular berbasis masalah keperawatan. Jakarta: EGC. ISBN:9790440200

Gunawan, I. (2007). Hipertensi tekanan darah tinggi. Yogyakarta: Penerbit Kansius.

Joseph, C.N., Cesare, P., Gaia,C., Nadia,C., Mara, M., Marco R., \& Luciano, B. (2006). Slow breathing improves arterial baroreflex sensitivity and decreases blood pressure in essential hypertension. AHA Journals, 4(6), 714-718. http://hyper.ahajournals.org/.

Kaushik, R. M., Kaushik, R., Mahajan, S. K., \& Rajesh, V. (2006). Effects of mental relaxation and slow breathing in essential hypertension. Complementary Therapies in Medicine, 14(2), 120-6. doi: http://dx.doi.org/10.1016/j.ctim.2005.11.007. 
Kementerian Kesehatan RI (Kemenkes RI). (2013). Riset Kesehatan Dasar Tahun 2013. Diakses melalui: //www.kemenkesri.go.id//rikesdas.doc.//pdf.

Martini, F. (2006). Fundamentals of anatomy \& physiology. Seventh Edition, Pearson: Benjamin Cummings.

Mason, H., Vandoni, M., deBarbieri, G., Codrons, E., Ugargol, V., \& Bernardi, L. (2013). Cardiovascular and respiratory effect of yogic slow breathing in the yoga beginner: What is the best approach?.Evidence - Based Complementary and Alternative Medicine, doi:http://dx.doi.org/10.1155/2013/743504

Potter, A.P., \& Perry, A. (2006). Fundamentals of nursing. $6^{\text {th }}$ Edition. Vol.1. Mosby: Louis Missouri.

Price, S. A., \& Wilson, L. M. (2006). Patofisiologi: Konsep klinis proses-proses penyakit, edisi 6, volume 1. Jakarta : EGC.

Sepdianto, T.C., Nurachmah, E., \& Gayatri, D. (2010). Penurunan tekanan darah dan kecemasan melalui latihan slow deep breathing pada pasien hipertensi primer. Jurnal Keperawatan Indonesia: 13(1), Hal 37-40. https://scholar.google.co.id/ jki.ui.ac.id.

Smetlzer \& Bare. (2011). Buku ajar keperawatan medikal bedah. Volume 2. Edisi 8. Jakarta: EGC.

Tambayong, J. (2010). Patofisiologi keperawatan. Jakarta: ECG.

World Health Organization (WHO). (2012). Non infection diseases progress. Diakses melalui: http://www.who.int/publication/. 